Review

\title{
The role of germ cell loss during primordial follicle assembly: a review of current advances
}

\author{
Yuan-Chao Sun ${ }^{1}$, Xiao-Feng Sun ${ }^{2}$, Paul W. Dyce ${ }^{3}$, Wei Shen ${ }^{2}$, Hong Chen ${ }^{1 凶}$ \\ 1. College of Animal Science and Technology, Northwest A\&F University, Shaanxi Key Laboratory of Molecular Biology for Agriculture, Yangling Shaanxi \\ 712100, China \\ 2. Institute of Reproductive Sciences, College of Animal Science and Technology, Qingdao Agricultural University, Qingdao 266109, China; \\ 3. Department of Animal Sciences, Auburn University, Auburn, AL 36849, USA \\ $\triangle$ Corresponding authors: Prof. Wei Shen E-mail: wshen@qau.edu.cn; shenwei427@163.com. Prof. Hong Chen E-mail: chenhong1212@263.net. \\ (C) Ivyspring International Publisher. This is an open access article distributed under the terms of the Creative Commons Attribution (CC BY-NC) license \\ (https://creativecommons.org/licenses/by-nc/4.0/). See http://ivyspring.com/terms for full terms and conditions.
}

Received: 2016.10.20; Accepted: 2017.01.25; Published: 2017.03.11

\begin{abstract}
In most female mammals, early germline development begins with the appearance of primordial germ cells (PGCs), and develops to form mature oocytes following several vital processes. It remains well accepted that significant germ cell apoptosis and oocyte loss takes place around the time of birth. The transition of the ovarian environment from fetal to neonatal, coincides with the loss of germ cells and the timing of follicle formation. All told it is common to lose approximately two thirds of germ cells during this transition period. The current consensus is that germ cell loss can be attributed, at least in part, to programmed cell death (PCD). Recently, autophagy has been implicated as playing a part in germ cell loss during the time of parturition. In this review, we discuss the major opinions and mechanisms of mammalian ovarian PCD during the process of germ cell loss. We also pay close attention to the function of autophagy in germ cell loss, and speculate that autophagy may also serve as a critical and necessary process during the establishment of primordial follicle pool.
\end{abstract}

Key words: Germ cell loss; Germ cell cyst; Apoptosis; Autophagy; Primordial follicle assembly

\section{Introduction}

In most mammals, it has been demonstrated that approximately $50 \%-70 \%$ of oocytes do not survive to reach maturity [1-5]. The transition of the ovarian environment from fetal to neonatal involves a change from nutritive ingestion via the maternal-fetal blood interface to lactation, and appears to be a critical factor influencing this process. Many organs, including the ovary, have to adapt to post-parturition starvation by non-apoptotic or apoptotic types of PCD [6], a crucial process that is necessary for physiological development. PCD can be classified into three categories: Type I involves apoptotic cell death, which morphologically features cell shrinkage and nuclear fragmentation, type II which morphologically features the formation of autophagic vacuoles, and type III involving necrotic cell death, which morphologically features plasma membrane breakdown [7].
Analysis of the mouse ovary confirms the decrease in the whole number of around birth, with about $40 \%$ - $50 \%$ reduction of follicles from 19.5 days post coitum (dpc) to 2 days post partum (dpp) [8]. Apoptosis is believed to be the major mechanism of germ cell loss in newborn ovaries [9-12]. The expression and balance of the apoptotic-related genes Bcl-2 and Bax are believed to regulate the apoptosis of germ cells [13-15]. In addition, increased lysosome amplification and the expression of LAMP1, suggests a probable role for autophagy in this process [8]. The process of germ cell death occurring during the shift between germ cyst breakdown and establishment of primordial follicle remains poorly understood. Furthermore, the mechanism by which germ cells are lost during the perinatal period remains largely undefined. Complex mechanisms and pathways are believed to function together in fetal and neonatal 
germ cell loss, and further work is needed to acquire a better understanding of this process.

Autophagy (type II PCD) is an evolutionarily conserved cellular process through which a cell degrades their own proteins, aggregates, or organelles and is seen in many species from yeast to mammals $[16,17]$. Autophagy is an important process that is necessary for normal development, remodeling of tissues or organs, and cell survival. Recent reports provide evidence that autophagy is a lysosome mediated degradation pathway [18-23]. In this review, we discuss the major opinions and mechanisms of mammalian ovarian PCD. We also pay close attention to the function of autophagy in germ cell loss, and propose that autophagy may also act as a critical and necessary process during establishment of the primordial follicle pool.

\section{Germ cell loss around birth}

In the female early germ cell development includes the formation of PGCs and their colonization in the gonadal ridges. Following colonization, the PGCs form oogonia and arrest at meiotic prophase I (MPI), and the germ cell cysts undergo breakdown during the establishment of primordial follicle. In the mouse PGCs, the precursors of both oocyte and sperm, begin to appear at about $7.25 \mathrm{dpc}$ [24]. Once PGCs are specified, they start to migrate from outside of the embryo at around $8.5 \mathrm{dpc}$ and arrive at the undifferentiated genital ridge at about 10.5-11.5 dpc [25]. The PGCs colonize and proliferate in the fetal gonadal tissues and then initiate the developmental programs of spermatogenesis or oogenesis. In the female oogonia, the mitotically active germ cells, expand their numbers within the developing fetal ovary. Once the female germ cells enter into meiotic prophase they stop mitotic proliferation and form germ cell cysts [26-28]. Around the time of birth the germ cell cysts undergo a process of degradation to form primordial follicles, during which some oocytes are enclosed by ovarian somatic cells but the majority die during the process of germ cell cyst breakdown.

Exact germ cell numbers prior to degradation has proven extremely difficult to determine. For example, when the gonad germ cells of $13.5 \mathrm{dpc}$ female mice were specifically labeled with a VASA antibody to recognize the total number of germ cells, it was determined that one gonad contained approximately 6,000 germ cells [4]; Conversely, when germ cells were identified by their high content of cytoplasmic alkaline phosphatase, they found one gonad contained 11000 germ cells at $13.5 \mathrm{dpc}[29,30]$. Morphological studies in mice have shown that cell death mainly occurs in oocytes at MPI from $16.5 \mathrm{dpc}$ to the early perinatal stage, generally in the first couple days following birth [31]. It was reported that the germ cell number decreases from about 12,000 at $13.5 \mathrm{dpc}$ to 3,500 - 4,000 three days following birth [4]. In the human fetus 7 million female germ cells develop initially in the gonadal ridges at about the $20^{\text {th }}$ week of gestation, however at birth only $1-2$ million viable oocytes remain (Fig. 1) [32]. The function and mechanism underlying germ cell loss remains poorly understood and requires further studies.

\section{PGCs formation and proliferation}
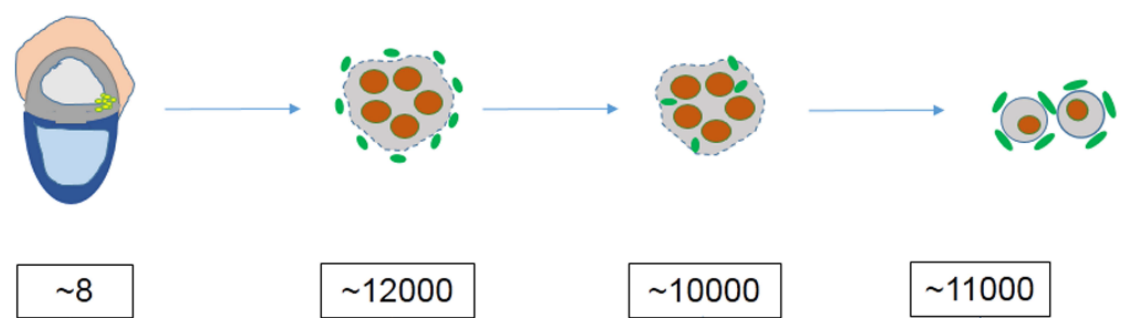

Mouse

$$
6.5 \mathrm{dpc}
$$

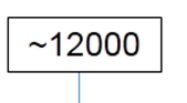

$13.5 \mathrm{dpc}$
Perinatal stage

abundant oocytes loss
Puberty and oestrous cycle

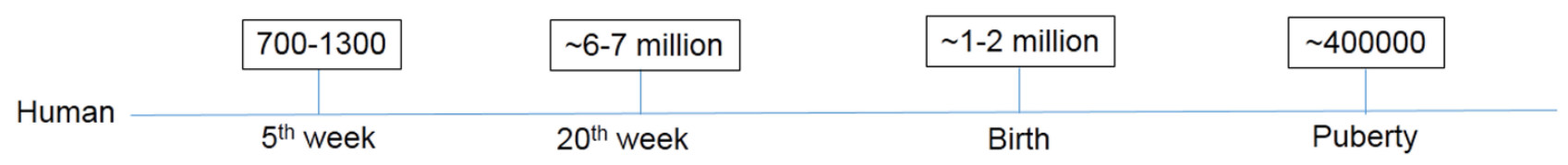

Figure 1. The number of germ cells in mouse and human ovaries at different stages. 


\section{Hypotheses of germ cell loss}

With the dramatic loss of germ cells taking place, prior to and during follicular assembly, the final number of follicles is not determined by the number of germ cells entering meiosis but the number of survived oocytes $[1,5]$. The mechanism or cause of this oocyte loss remains largely unknown. There is no evidence that only one factor or pathway can explain the entire germ cell loss in the fetal ovary. It is well accepted that PCD can be triggered by all kinds of intra and extracellular stresses including DNA damage, hypoxia, or growth factor withdrawal. Currently three hypotheses have been proposed to explain germ cell loss during this process.

The first hypothesis involves the limited amounts of trophic factors. Similar to other cell types the development and survival of germ cells depends on growth factors, and in most cases, an indigent supply of trophic factors would determine whether an oocyte enters apoptosis [8]. Supporting this hypothesis PGCs have been reported to suffer apoptosis with a lack of certain trophic factors, such as leukemia inhibitory factor (LIF) [34]. It has also been shown that Kit and its ligand stem cell factor (SCF) are essential for the survival of germ cells in vivo [35-38]. The access to trophic factors is altered with the transition of nutritive ingestion, from blood circulation to lactation, which is sufficient to influence the survival of germ cells. The second hypothesis involves a selection mechanism to guarantee the quality of oocytes by removing germ cells with genetic or meiotic pairing errors [28]. Finally, the third hypothesis suggests a more altruistic purpose for germ cells undergoing PCD. It proposes that the dying oocyte may act as a nurse cell supplying nutrition and energy to developing surviving oocytes [4]. Some evidence suggests that oocytes die in order to donate their cellular components and metabolites to surviving oocytes within a given cyst. However, none of these hypotheses can sufficiently explain the oocyte loss seen in fetal ovaries on their own. It is likely a combination of all these hypotheses playing a role in the dramatic loss of germ cells seen during ovarian development. Currently, the pathways as well as the individual signaling molecules involved in oocyte elimination remain largely unknown. Currently studies utilizing genetic mutations or the overexpression of various molecules, involved in the apoptosis pathway, have generated controversial results.

\section{Multiple mechanisms of germ cell loss during primordial follicle assembly}

Understanding the mechanisms involved in oocyte loss are particularly important in attempting to increase the oocyte pool and thereby, reproductive lifespan of an organism. Apoptosis has been implicated as playing a major role in germ cell death observed in neonatal ovaries. However, increased LAMP1 expression has been documented suggesting a probable role of autophagy in this process. During the establishment of primordial follicles, it is likely germ cells may require the cooperation of multiple mechanisms to ensure the survival of chosen oocytes.

\section{Apoptosis and its function during germ cell loss}

Generally, early germ cell loss occurs at two critical time points during development: (1) during meiotic prophase I, germ cell cyst breakdown in the prenatal and newborn ovaries, as well as the establishment of primordial follicles; (2) follicular atresia taking place during the ovulatory cycle [39].

Apoptosis was found to play a role at both time points [40]. Apoptosis, one type of PCD, is involved in the normal development process of many tissues. It has the morphologically features of nuclear fragmentation followed cell breakdown into a number of apoptotic bodies, and it is believed to function in the control of cell numbers in most organs [40-42]. Many studies have demonstrated that apoptosis functions a lot throughout the process of oocytes loss seen in the fetal mammalian ovaries.

During mammalian oogenesis oocyte loss occurs particularly at the pachytene stage of meiosis, with several reports suggesting apoptosis is playing a major role $[3,10]$. In mice a number of $13.5 \mathrm{dpc}$ female germ cells was observed to live with reduced DNA content, and the number of them increased in 15.5 to $17.5 \mathrm{dpc}$ fetal ovaries $[43,44]$. Others have demonstrated that DNA fragmentation was also detected by TUNEL stain in fetal ovaries and ranged from about 0.5 to $5 \%$ [45-46]. In addition to the fetal ovaries it was also shown that apoptosis occurs in germ cells predominantly of newborn mouse ovaries from 1 to 3 days following birth [4]. Some reports have revealed the involvement of the three apoptosis-associated genes Bcl2, Bax, and Caspase2 in impacting germ cell numbers in the fetal ovaries [13-15]. Other studies have also demonstrated that mammalian BCL-2 and BAX proteins regulate germ cell loss in fetal ovaries [47-49]. Albamonte et al. detected the expression of VASA, BAX, and BCL-2 in human fetal ovaries and revealed that high expression of both BAX and BCL-2 was found within female germ cells from week 12, while BCL-2 was undetectable from week 17. This suggests that the maximum number of apoptotic germ cells coincides with the expression of the BCL-2 protein, and the 
balance between apoptosis-inhibition BCL-2 and apoptosis-induction BAX determines germ cell survival or death [50]. Therefore, it appears that apoptosis plays a significant role during primordial follicular assembly, though it remains unknown how it is regulated.

\section{Germ cell cyst breakdown and germ cell loss}

In mice, the establishment of primordial follicle pool and germ cell cyst breakdown occur in concert, suggesting a link between them. Throughout the transition from oogonia to oocyte both apoptosis and autophagy can be detected (Fig. 2). However, the significance of the role they play in germ cell cyst breakdown and follicular assembly remain poorly defined. In mice, PGCs start to express germ cell-specific genes including Mvh at about 10.5 - 11.5 dpc, and at about 12.5 - 13.5 dpc some PGCs, now referred as oogonia, enter into the first meiotic division prophase and develop into clusters called germ cell cysts [51, 52].

Because of incomplete cytokinesis germ cells within cysts divide synchronously but remain connected with each other by intercellular bridges during oogonial division. It was reported that in Drosophila, one oogonia would undergo mitotic divisions and form a 16 cell cyst, but in the end only one of them will develop into an oocyte while the rest act as nurse cells to supply nutrients for the chosen

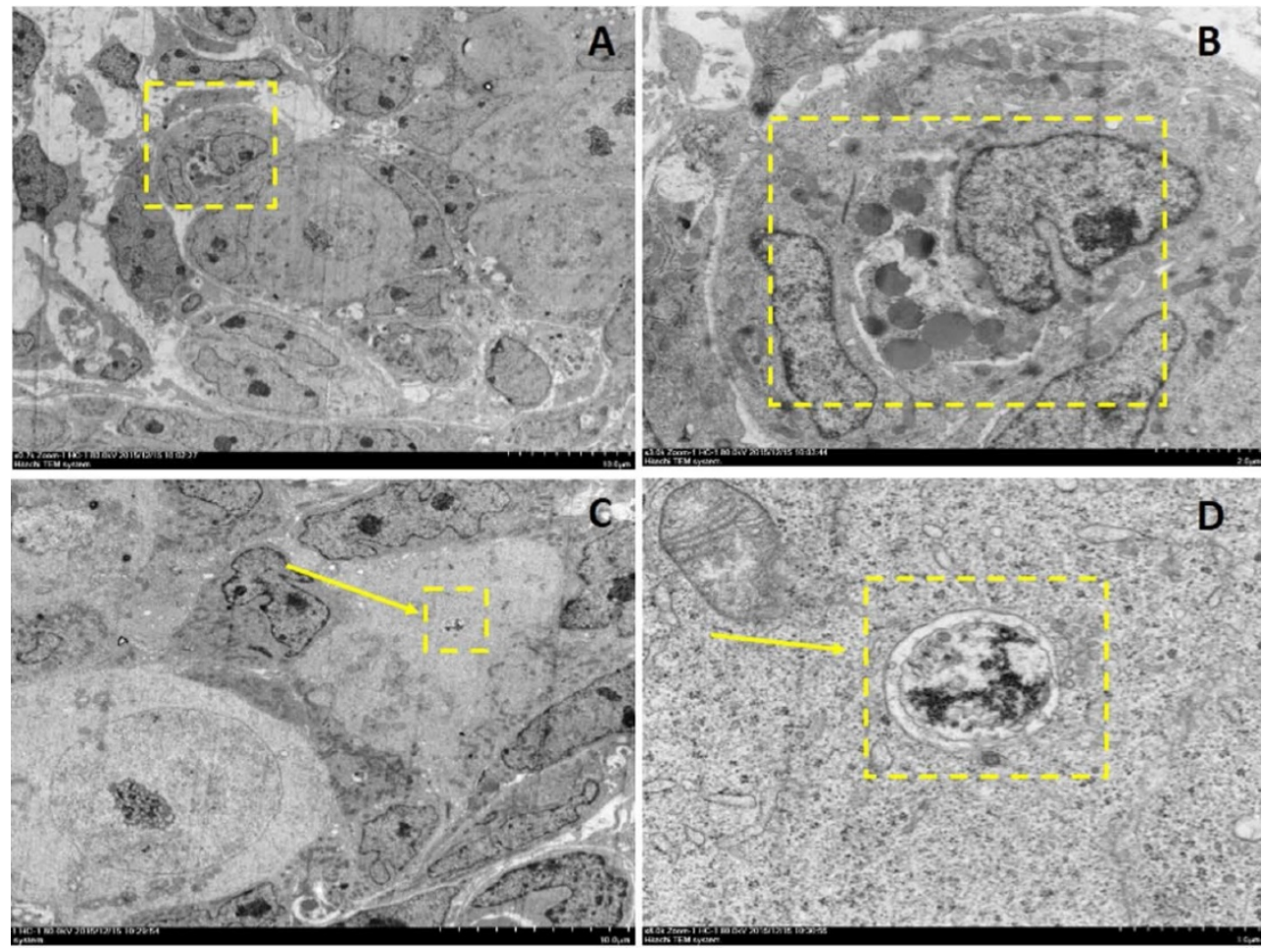

Figure 2. Electron microscopy depictions of apoptosis and autophagy in 2dpp mouse germ cell cysts. A depicts a 2-cell germ cyst within which one is undergoing apoptosis. B depicts the magnified section denoted by the dashed yellow box in A. $C$ and $D$ depict an autophagosome observed in a germ cell within a cyst. one [53]. This process is not as well understood in mice and remains poorly defined. Lei et al. developed a single-germ-cell tracking method allowing the lineage of marked germ cells to be detected during development and found that following labeling at $10.5 \mathrm{dpc}$, all the germ cell clones $(100 \%)$ contained labeled cells in one, two, four or eight cell containing cysts. At 12.5 dpc most of them contained four, eight and 16 cells, suggesting continued cyst production [54]. The germ cells within the cysts were shown to be connected via intercellular bridges. Using electron microscopy, Pepling et al. observed many examples of intercellular bridges in $11.5 \mathrm{dpc}$ to $17.5 \mathrm{dpc}$ ovaries. These bridges are similar in appearance and size to those described in previous studies of mammalian germ cells [55]. The Balbiani body is reported to be a distinctive organelle aggregate containing mitochondria, ER, and granulofibrillar material (GFM) that is observed in early oocytes of different species [56-58]. The mouse Balbiani body forms prior to the primordial follicles formation and is only short-lived within young oocytes. It is demonstrated that in mice early germ cells build the Balbiani body to form oocytes receiving energy and nutrients from the cyst-sister cells, whereas the cyst-sister germ cells die, thereby acting as nurse-like cells [59].

In mammals, during the formation of primordial follicles, oocytes are enclosed and separated by invading granulosa cells to form independent primordial follicles. It has been proposed that there are ovarian regional differences during the establishment of primordial follicles. In mice, it was reported that this process of breakdown begins at 17.5 dpc mainly in the medullary part of the ovaries $[2,9]$.

\section{Growth factors and signaling molecules of germ cell loss during primordial follicle assembly}

PGCs were reported to enter apoptosis with the lack of trophic factors including LIF and SCF [34, 35]. Several growth factors have been reported to be important for follicle formation. 
Wang et al. cultured fetal mouse ovaries for 9 days in vitro to match the time when distinct primordial germ cells could be detected and they found that adding SCF significantly stimulated the primordial follicle formation. In contrast to SCF, growth differentiation factor-9 (GDF-9) showed dose-dependent stimulation following the formation of the primordial follicles. Adding GDF-9, at a low-dose, stimulated the development of primary follicles leading to a slight decrease in primordial follicle number, but a high dose of GDF-9 surprisingly increased the percentage of both primordial and primary follicles [61]. As mentioned, KIT signaling has also been reported to play a role during several phases of ovarian development. In Reynaud's study heterozygous mice carrying the mutation $\mathrm{Kit}^{\mathrm{W}-\text {-lacZ }}$ had decreased KIT and SCF and were used to explore the function of KIT signaling. Compared with the control group they found folliculogenesis of the heterozygous $\mathrm{Kit}^{\mathrm{W}-\mathrm{lacZ} /+}$ mice was disturbed including oocyte growth, and the proliferation of granulosa cells [62].

There is growing evidence that the transforming growth factor (TGF) superfamily plays an important role during primordial follicular assembly [63]. To study the role of multiple TGF- $\beta$ family members in the formation of primordial follicles bone morphogenetic protein 15 (BMP15) or GDF9 knockout mice were used. GDF-9 mutant mice showed infertile due to a failure in primary follicle formation. While BMP15 null females are subfertile with minimal dysfunction in their ovaries. They also found that BMP15 and GDF9 double homozygous females display oocyte loss at the primary follicle stage, resembling the GDF-9 mutants [64]. When mouse ovaries were exposed to Activin A (ActA), another member of TGF- $\beta$ family, they showed an increase in the primordial follicle numbers [65]. Liang et al. cultured fetal mice ovaries of $12.5 \mathrm{dpc}$ adding ActA for 28 days in vitro to explore the effects of ActA during early development of oocytes. In accordance with the previous results they found that the ovaries treated with ActA showed a higher number of oocytes with better growth. Furthermore, when $12.5 \mathrm{dpc}$ ovaries were cultured in vitro with the adding of ActA for 10 days, they showed less germ cell death and more primordial follicle survival compared to the control group [66].

To our knowledge, Notch signaling pathway is important for the formation of primordial follicles. Wang et al. isolated and cultured $2 \mathrm{dpp}$ mouse ovaries in vitro by adding DAPT or L-685,458, to examine the role of Notch signaling during primordial follicle assembly, which are inhibitors of Notch pathway. They found that adding DAPT or L-685,458 significantly decreased the expression of Notch pathway components, including Notch1, Notch2, Jagged1 and Jagged2. Following a 5-day culture mouse ovaries treated with DAPT showed a decreased number of growing follicles compared with the control, however, the primordial follicle number was higher than in the control group. Similarly, treatment with L-685,458 displayed consistent results as with DAPT. Nevertheless, the total number of oocytes in ovaries that were cultured with inhibitors of Notch pathway, was significantly reduced compared with the control group. According to these results, the process of primordial follicle assembly was also effected by regulation of the Notch signaling pathway [67].

Besides endogenous growth factors and signaling pathways the external environment and oestrogen-like hormones can also affect the formation of primordial follicles. For example, Bisphenol A (BPA), a synthetic additive that is ubiquitous in our everyday environment, was noted to have effects on mammalian reproductive functions. Zhang et al. found that early development of oocyte was significantly depressed when the newborn mice ovaries were cultured in vitro by adding BPA and diethylhexyl phthalate (DEHP) [68]. Another study revealed that BPA influenced oocyte growth through the hypomethylation of imprinted genes including Peg3 and Igf2r, as well as the enhanced estrogen receptor (ER) expression [69]. Although a limiting supply of trophic factors may be one of the causes of fetal germ cell loss, the underlying mechanisms and molecular pathways and the link to PCD remain unclear.

\section{A potential mechanism: autophagy and its function during germ cell loss}

Autophagy is a conserved mechanism for the bulk recycling of proteins and organelles. Although a number of studies have demonstrated that apoptosis plays a role in oocyte loss during follicular assembly other mechanisms have also been implicated. Lobascio et al. proposed a different mechanism of PCD operating during follicular assembly, namely autophagy [70]. The occurrence of LAMP1 expression during follicular assembly suggests a role for autophagy, which is controlled by insulin/target of rapamycin (TOR) signaling [71-73]. In Drosophila nutrient depletion induced autophagy and TOR signaling has been shown to influence the function and structure of the ovaries [74-77]. Furthermore, Drosophila ovaries develop abnormally when lacking autophagy-related gene (ATG) in the germline cells and follicle cells. This suggests a relationship between autophagy and germ cell development. It was reported that autophagy is also important for 
spermatogenesis. Wang et al. reported that the knockout of autophagy-related gene 7 (Atg7) specifically in germ cells will result in infertility in female mice. Knock-out of Atg7 failed to affect the early development of spermatogenesis but impeded the formation of the acrosomal vesicle. Further study found that Atg7 depleted germ cells showing disruption in the autophagic flux, and resulted in an abnormality of conjugation between LC3 and Golgi apparatus-derived vesicles [78]. These findings uncovered a new role for ATG in germ cell development.

Similarly, some reports demonstrated that autophagy appeared to exist and play an important role in mammalian germ cell loss [18-23]. Studies looking at mouse fetal oocyte loss found that adding rapamycin, an inhibitor of mTOR signaling, increased the number of TUNEL positive germ cells presumably lowering the amount of autophagy (De Felici et al. 2008). Along with this the relatively less number of apoptotic cells seen in fetal ovaries suggests that additional mechanisms of PCD may be involved in germ cell loss [8].

Autophagy was found to play an important role in follicular atresia, particularly in primordial and primary follicles, in the spiny mouse [80]. In addition, ultrastructural observation of ovaries has demonstrated the existence of autophagosomes and lysosomes in the majority of species [81, 82]. In accordance with previous studies Rodrigues et al. explored the role of autophagy during the early germ cell loss through LAMP1 immunocytochemistry and special markers of lysosomes, investigating the lysosome amplification of oocytes around the time of birth. Firstly, oocytes enclosed within primordial follicles showed an apparent lysosomal accumulation when compared to those extruded or undergoing PCD. Secondly, prominent expression of $L C-3 B$ and Beclin 1 were found in $19.5 \mathrm{dpc}$ ovaries, $2 \mathrm{dpp}$ and 6 $\mathrm{dpp}$, whereas Caspase-3 is present in fetal mice ovaries only [8]. These results support the role of lysosome mediated autophagy in germ cell loss.

Gawriluk et al. found that interdicting autophagy by knocking out of Beclin1 or Atg7, resulted in an over loss of oocytes within the perinatal ovary. The number of germ cells in Beclin1 null 1 dpp ovaries showed a $50 \%$ - $60 \%$ reduction compared to normal wildtype ovaries. Whereas Atg7 null ovaries at this stage lack discernable germ cells. Their study suggested that autophagy acts as a cell survival mechanism during germ cell loss and oocyte survival in the mouse ovary [18].

To confirm the involvement of autophagy during rat oogenesis, Choi et al. investigated the expression of LC3 in immature rat ovaries to determine the site of autophagy in follicular cells. They found that primordial follicles showed weak LC3 expression. Conversely, primary and preantral follicles exhibited very intense immunoreactivity for LC3. In addition, granulosa cells of atretic follicles were identified that showed intense Caspase-3 and LC3 staining, indicating that autophagy has a good correlation with apoptosis. [22]. In another study a germ cell specific Atg7 null-mutation was demonstrated to cause subfertility due to loss of follicles. When Atg7 was knocked out in $17.5 \mathrm{dpc}$ mouse ovaries, the expression of LC3 decreased significantly compared to wildtype ovaries. Similarly, Atg7 Tnap-Cre ovaries showed a significant reduction of about $50 \%$ in the number of oocytes and follicles when compared with the control ovaries. When Atg7 Tnap-Cre neonatal mouse ovaries were cultured under a starvation condition in vitro the oocytes and follicles were reduced drastically compared with the control group [23]. All of these results suggest that autophagy protects germ cells from loss in the neonatal ovaries under starvation conditions. Further investigation revealed that autophagy inhibition will lead to oocyte death by apoptosis in cultured ovaries in vitro, suggesting a close connection between autophagy and apoptosis.

\section{Conclusions}

In most female mammals, it has been well accepted that significant germ cell loss occurs shortly after birth [1-5]. While it is generally accepted that germ cell and oocyte loss involves the concerted effort of several processes, the exact underlying mechanisms remain unknown. Apoptosis is an evolutionarily conserved genetically regulated cell removal system which is morphologically distinct from necrosis. A majority of studies have demonstrated that germ cell loss takes place through apoptosis in fetal and neonatal mammalian ovaries. Three apoptosis-associated genes Bcl2, Bax, and Caspase-2, and the balance between BAX and BCL-2 proteins is believed to determine the death or survival of germ cells. TUNEL-positive oocytes observed in fetal mouse ovaries also suggest the role of apoptosis during germ cell loss. The surviving germ cells within cysts are reported to build a Balbiani body and receive nutrients and organelles from cyst-sister cells, whereas the sister germ cells die acting as nurse cells $[83,84]$. Growth factors are important and necessary for germ cell development and survival, and a limited supply or change in levels might influence the survival of oocytes. Signaling pathways, aspects of the external environment, and oestrogen-like hormones may also affect the formation of primordial follicles. Autophagy is also reported to play a part in the 
process of germ cell and oocyte loss. The observation of autophagosomes and lysosomes in many species ovaries provides support for this assertion. Furthermore, Atg7 and Beclin1 knockout studies display the crucial role of autophagy during germ cell loss during the transition from the fetal to newborn stages.

In summary, it is clear a level of complexity involving multiple mechanisms is involved in the establishment of primordial follicles (Fig. 3). The relative contributions of growth factors, apoptosis, autophagy, along with other mechanisms may vary at distinct stages during ovarian development. Future studies directed at improving the reproductive lifespan need to take these diverse mechanisms into account and understand how they work together during every stage over the development of most mammalian ovaries.

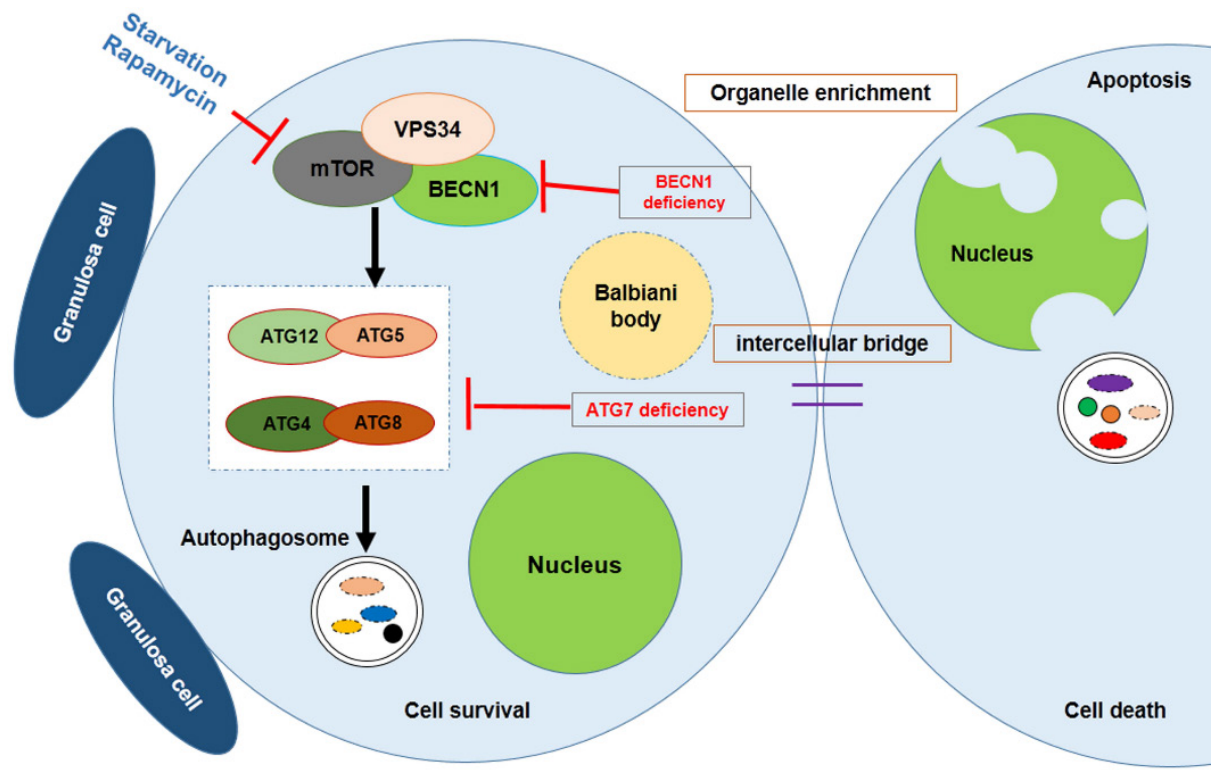

Figure 3. Survival of the chosen oocyte, showing that the mouse germ cells receive organelles from neighboring cyst cells and build a Balbiani body to become oocytes. Autophagy is regulated by mTOR signaling; Atg7 or BECNI deficiency will interdict the formation of the autophagosome, causing germ cell loss.

Table 1. Major studies of germ cell loss in the mammalian ovary

\begin{tabular}{|c|c|c|c|c|}
\hline Researcher & Species & Mechanism involved & The experimental introduction & Year \\
\hline De Pol et al. & Human & Apoptosis & $\begin{array}{l}\text { Numerical decrease of human female germ cells during the fetal period is due } \\
\text { to apoptosis }\end{array}$ & 1997 \\
\hline De Felici et al. & Mouse & $\begin{array}{l}\text { Bcl-2 and Bax regulation of apoptosis } \\
\text { under a partial control by SCF }\end{array}$ & $\begin{array}{l}\text { Elimination of excrescent oocytes might be an apoptotic phenomenon } \\
\text { controlled by SCF availability }\end{array}$ & 1999 \\
\hline Pepling et al. & Mouse & Germ cyst breakdown and apoptosis & Germ cell cysts undergo programmed breakdown to form primordial follicles & 2001 \\
\hline McClellan et al. & Mouse & GCNA-1 & Quantify continuous oocyte loss throughout MPI using GCNA-1 & 2003 \\
\hline Jefferson et al. & Mouse & $\begin{array}{l}\text { Germ cyst breakdown and the } \\
\text { formation of MOFs }\end{array}$ & $\begin{array}{l}\text { Genistein treatment inhibits germ cell breakdown and increases oocyte } \\
\text { survival }\end{array}$ & 2005 \\
\hline Pepling et al. & Mouse & Balbiani body & oocytes contain a Balbiani body & 2006 \\
\hline Michelle et al. & Mouse & BAX-independen apoptosis & $\begin{array}{l}\text { While progressing through meiotic prophase, oocytes are eliminated by a } \\
\text { BAX-independent mechanism }\end{array}$ & 2006 \\
\hline Bristol-Gould et al. & Mouse & ActA & ActA increased the number of postnatal mouse primordial follicles & 2006 \\
\hline Chen et al & Mouse & $\begin{array}{l}\text { Germ cyst breakdown and the } \\
\text { formation of MOFs }\end{array}$ & Estradiol, progesterone and genistein inhibit germ cyst breakdown & 2007 \\
\hline Ghafari et al. & Mouse & Apoptosis & $\begin{array}{l}\text { Apoptosis occur throughout MPI in fetal and postnatal oocytes, with greatest } \\
\text { incidence at diplotene stage }\end{array}$ & 2007 \\
\hline Lobascio et al. & Mouse & Germ cell apoptosis & Fetal oocytes undergo degeneration mostly by apoptosis & 2007 \\
\hline Albamonte et al. & Mouse & $\begin{array}{l}\text { BCL-2/BAX expression balance and } \\
\text { apoptosis }\end{array}$ & apoptotic germ cells was coincident with the lack of detectable BCL-2 protein & 2008 \\
\hline Wen et al. & Mouse & The expression of PAR6 & $\begin{array}{l}\text { PAR6, a potential marker for the germ cells celected to form Primordial } \\
\text { Follicles }\end{array}$ & 2009 \\
\hline Rodrigues et al. & Mouse & Germ cell apoptosis and autophagy & $\begin{array}{l}\text { Multiple perinatal mechanisms establish the primordial follicle } \\
\text { reserve in mice }\end{array}$ & 2009 \\
\hline Lei et al. & Mouse & $\begin{array}{l}\text { Cyst fragmentation and germ cell } \\
\text { apoptosis }\end{array}$ & $\begin{array}{l}\text { PGCs initially develop into cysts that undergo fragmentation into smaller cysts } \\
\text { prior to meiotic entry }\end{array}$ & 2013 \\
\hline Song et al. & Mouse & Autophagy & Atg7 knockout resulted in germ cell over-loss at the neonatal transition period & 2015 \\
\hline Lei et al. & Mouse & Cytoplasmic and organelle transport & $\begin{array}{l}\text { germ cells receive organelles from sister cyst cells to become oocytes, nurse-like } \\
\text { germ cells die }\end{array}$ & 2016 \\
\hline
\end{tabular}




\section{Acknowledgements}

This work was supported by National Nature Science Foundation of China (31471346 and 31671554) and National Basic Research Program of China (973 Program, 2012CB944401) to W. Shen.

\section{Competing Interests}

The authors have declared that no competing interest exists.

\section{References}

1. Borum K. Oogenesis in the mouse. A study of the meiotic prophase. Exp Cell Res. 1961; 24:495-507.

2. McClellan KA, Gosden R, Taketo T. Continuous loss of oocytes throughout meiotic prophase in the normal mouse ovary. Dev Biol. 2003; 258:334-348.

3. Morita Y, Tilly JL. Oocyte apoptosis: like sand through an hourglass. Dev Biol. 1999; 213:1-17.

4. Pepling ME, Spradling AC. Mouse ovarian germ cell cysts undergo programmed breakdown to form primordial follicles. Dev Biol. 2001; 234:339-351.

5. Baker TG. Oogenesis and ovarian development. In: Balin H and Glasser S, Eds. Reproductive Biology. Amsterdam: Excerpta Medica. 1972.

6. Edinger AL, Thompson $\mathrm{CB}$. Death by design: apoptosis, necrosis and autophagy. Curr Opin Cell Biol. 2004; 16:663-669.

7. Sato A, Omi T, Yamamoto A, Satake A et al. MicroRNA-351 Regulates Two-Types of Cell Death, Necrosis and Apoptosis, Induced by 5-fluoro-2'-deoxyuridine. PLoS One. 2016; 11:e0153130.

8. Rodrigues P, Limback D, McGinnis LK et al. Multiple mechanisms of germ cell loss in the perinatal mouse ovary. Reproduction. 2009; 137:709-720.

9. De Pol A, Vaccina F, Forabosco A et al. Apoptosis of germ cells during human prenatal oogenesis. Hum Reprod. 1997; 12:2235-2241.

10. Matikainen TM, Moriyama T, Morita Y et al. Ligand activation of the aromatic hydrocarbon receptor transcription factor drives Bax-dependent apoptosis in developing fetal ovarian germ cells. Endocrinology. 2002; 143:615-20.

11. De Felici M, Klinger FG, Farini D et al. Establishment of oocyte population in the fetal ovary: primordial germ cell proliferation and oocyte programmed cell death. Reprod Biomed Online. 2005; 10:182-191.

12. Xu B, Hua J, Zhang Y et al. Proliferating cell nuclear antigen (PCNA) regulates primordial follicle assembly by promoting apoptosis of oocytes in fetal and neonatal mouse ovaries. PLoS One. 2011; 6:e16046.

13. Boumela I, Guillemin Y, Guérin JF et al. The Bcl-2 family pathway in gametes and preimplantation embryos. Gynecol Obstet Fertil. 2009; 37:720-32.

14. Felici MD, Carlo AD, Pesce $\mathrm{M}$ et al. Bcl-2 and Bax regulation of apoptosis in germ cells during prenatal oogenesis in the mouse embryo. Cell Death Differ. 1999; 6:908-915.

15. Alton M, Taketo T. Switch from BAX-dependent to BAX-independent germ cell loss during the development of fetal mouse ovaries. J Cell Sci. 2007; 120:417-424

16. Esclatine A, Chaumorcel M, Codogno P. Macroautophagy signaling and regulation. Curr Top Microbiol Immunol. 2009; 335:33-70.

17. Klionsky DJ. The molecular machinery of autophagy: unanswered questions. J Cell Sci. 2005; 118:7-18.

18. Gawriluk TR, Hale AN, Flaws JA et al. Autophagy is a cell survival program for female germ cells in the murine ovary. Reproduction. 2011; 141:759-765.

19. Barth JM, Szabad J, Hafen E et al. Autophagy in Drosophila ovaries is induced by starvation and is required for oogenesis. Cell Death Differ. 2011; 18:915-924.

20. Escobar ML, Echeverría OM, Ortíz $R$ et al. Combined apoptosis and autophagy, the process that eliminates the oocytes of atretic follicles in immature rats. Apoptosis. 2008; 13:1253-1266.

21. Tanner EA, Blute TA, Brachmann CB et al. Bcl-2 proteins and autophagy regulate mitochondrial dynamics during programmed cell death in the Drosophila ovary. Development. 2011; 138:327-338.

22. Choi JY, Jo MW, Lee EY et al. The role of autophagy in follicular development and atresia in rat granulosa cells. Fertil Steril. 2010; 93:2532-2537.

23. Song ZH, Yu HY, Wang P et al. Germ cell-specific Atg7 knockout results in primary ovarian insufficiency in female mice. Cell Death Dis. 2015; 6:e1589.

24. Ginsburg M, Snow MH, McLaren A. Primordial germ cells in the mouse embryo during gastrulation. Development. 1990; 110:521-528.

25. Tam PP, Snow MH. Proliferation and migration of primordial germ cells during compensatory growth in mouse embryos. J Embryol Exp Morphol. $1981 ; 64: 133-147$

26. Buehr M. The primordial germ cells of mammals: some current perspectives. Exp Cell Res. 1997; 232:194-207.

27. Briggs DA, Sharp DJ, Miller D et al. Transferrin in the developing ovarian follicle: evidence for de-novo expression by granulosa cells. Mol Hum Reprod. 1999; 5:1107-1114.
28. Tilly JL. Commuting the death sentence: how oocytes strive to survive. Nat Rev Mol Cell Biol. 2001; 2:838-848

29. Burgoyne PS, Baker TG. Oocyte depletion in XO mice and their XX sibs from 12 to 200 days post partum. J Reprod Fertil. 1981; 61:207-212

30. Chuva de Sousa Lopes SM, van den Driesche S, Carvalho RL et al. Altered primordial germ cell migration in the absence of transforming growth factor beta signaling via ALK5. Dev Biol. 2005; 284:194-203.

31. Bakken AH, McClanahan M. Patterns of RNA synthesis in early meiotic prophase oocytes from fetal mouse ovaries. Chromosoma. 1978; 67:21-40.

32. Baker TG. A quantitative and cytological study of germ cells in human ovaries. Proc R Soc Lond B Biol Sci. 1963; 158:417-433.

33. Ortiz R, Echeverría OM, Salgado R et al. Fine structural and cytochemical analysis of the processes of cell death of oocytes in atretic follicles in new born and prepubertal rats. Apoptosis. 2006; 11:25-37.

34. De Felici M, Dolci S. Leukemia inhibitory factor sustains the survival of mouse primordial germ cells cultured on TM4 feeder layers. Dev Biol. 1991; 147:281-284

35. Huang E, Nocka K, Beier DR et al. The hematopoietic growth factor KL is encoded by the $\mathrm{Sl}$ locus and is the ligand of the c-kit receptor, the gene product of the W locus. Cell. 1990; 63:225-233.

36 Brannan CI, Lyman SD, Williams DE et al. (1991). Steel-Dickie mutation encodes a c-kit ligand lacking transmembrane and cytoplasmic domains. Proc Natl Acad Sci U S A. 1991; 88:4671-4674.

37. Zsebo KM, Williams DA, Geissler EN et al. Stem cell factor is encoded at the Sl locus of the mouse and is the ligand for the c-kit tyrosine kinase receptor. Cell. 1990; 63:213-224.

38. Chabot B, Stephenson DA, Chapman VM et al. The proto-oncogene c-kit encoding a transmembrane tyrosine kinase receptor maps to the mouse $\mathrm{W}$ locus. Nature. 1988; 335:88-89.

39. Ghafari F, Gutierrez CG, Hartshorne GM. Apoptosis in mouse fetal and neonatal oocytes during meiotic prophase one. BMC Dev Biol. 2007; 7:87.

40. Hussein MR. Apoptosis in the ovary: molecular mechanisms. Hum Reprod Update. 2005; 11:162-177.

41. Kerr JF, Wyllie AH, Currie AR. Apoptosis: a basic biological phenomenon with wide-ranging implications in tissue kinetics. Br J Cancer. 1972; 26:239-257.

42. Wyllie AH. Apoptosis (the 1992 Frank Rose Memorial Lecture). Br J Cancer. 1993; 67:205-208

43. Coucouvanis EC, Sherwood SW, Carswell-Crumpton C et al. Evidence that the mechanism of prenatal germ cell death in the mouse is apoptosis. Exp Cell Res. 1993; 209:238-247.

44. Ratts VS, Flaws JA, Kolp R et al. Ablation of bcl-2 gene expression decreases the numbers of oocytes and primordial follicles established in the post-natal female mouse gonad. Endocrinology. 1995; 136:3665-3668.

45. Reynaud K, Nogueira D, Cortvrindt R et al. Confocal microscopy: principles and applications to the field of reproductive biology. Folia Histochem Cytobiol. 2001; 39:75-85.

46. Pesce M, Di Carlo A, De Felici M. The c-kit receptor is involved in the adhesion of mouse primordial germ cells to somatic cells in culture. Mech Dev. 1997; 68:37-44.

47. Bergeron L, Perez GI, Macdonald G et al. Defects in regulation of apoptosis in caspase-2-deficient mice. Genes Dev. 1998; 12:1304-1314.

48. Rucker EB 3rd, Dierisseau P, Wagner KU et al. Bcl-x and Bax regulate mouse primordial germ cell survival and apoptosis during embryogenesis. Mol Endocrinol. 2000; 14:1038-1052.

49. Greenfeld $\mathrm{CR}$, Pepling ME, Babus JK et al. BAX regulates follicular endowment in mice. Reproduction. 2007; 133:865-876.

50. Albamonte MS, Willis MA, Albamonte MI et al. The developing human ovary: immunohistochemical analysis of germ-cell-specific VASA protein, BCL-2/BAX expression balance and apoptosis. Hum Reprod. 2008; 23:1895-1901.

51. Büning J. The Insect Ovary: Ultrastructure, previtellogenic growth and evolution. New York: Chapman and Hall. 1994

52. de Cuevas M, Lilly MA, Spradling AC. Germline cyst formation in Drosophila. Annu Rev Genet. 1997; 31:405-428.

53. Jenkins VK, Timmons AK, McCall K. Diversity of cell death pathways: insight from the fly ovary. Trends Cell Biol. 2013; 23:567-574.

54. Lei L, Spradling AC. Mouse primordial germ cells produce cysts that partially fragment prior to meiosis. Development. 2013 140:2075-2081.

55. Pepling ME, Spradling AC. Female mouse germ cells form synchronously dividing cysts. Development. 1998; 125:3323-3328.

56. de Smedt V, Szöllösi D, Kloc M. The balbiani body: asymmetry in the mammalian oocyte. Genesis. 2000; 26:208-212.

57. Guraya SS. Recent advances in the morphology, cytochemistry, and function of Balbiani's vitelline body in animal oocytes. Int Rev Cytol. 1979; 59:249-321.

58. Kloc M, Bilinski S, Etkin LD. The Balbiani body and germ cell determinants: 150 years later. Curr Top Dev Biol. 2004; 59:1-36.

59. Pepling ME, Wilhelm JE, O'Hara AL et al. Mouse oocytes within germ cell cysts and primordial follicles contain a Balbiani body. Proc Natl Acad Sci U S A. $2007 ; 104: 187-192$.

60. Pepling ME, Sundman EA, Patterson NL, Gephardt GW, Medico L Jr, Wilson KI. Differences in oocyte development and estradiol sensitivity among mouse strains. Reproduction. 2010; 139:349-357. 
61. Wang J, Roy SK. Growth differentiation factor-9 and stem cell factor promote primordial follicle formation in the hamster: modulation by follicle-stimulating hormone. Biol Reprod. 2004; 70:577-585.

62. Reynaud K, Cortvrindt R, Smitz J et al. Alterations in ovarian function of mice with reduced amounts of KIT receptor. Reproduction. 2001; 121:229-237.

63. Trombly DJ, Woodruff TK, Mayo KE. Roles for transforming growth factor beta superfamily proteins in early folliculogenesis. Semin Reprod Med. 2009; 27:14-23.

64. Yan C, Wang P, DeMayo J et al. Synergistic roles of bone morphogenetic protein 15 and growth differentiation factor 9 in ovarian function. Mol Endocrinol. 2001; 15:854-866.

65. Bristol-Gould SK, Kreeger PK, Selkirk CG et al. Postnatal regulation of germ cells by activin: the establishment of the initial follicle pool. Dev Biol. 2006; 298:132-148.

66. Liang GJ, Zhang XF, Wang JJ et al. Activin A accelerates the progression of fetal oocytes throughout meiosis and early oogenesis in the mouse. Stem Cells Dev. 2015; 24:2455-2465.

67. Wang LQ, Liu JC, Chen CL et al. Regulation of primordial follicle recruitment by cross-talk between the Notch and phosphatase and tensin homologue (PTEN)/AKT pathways. Reprod Fertil Dev. 2016; 28:700-712.

68. Zhang T, Li L, Qin XS et al. Di-(2-ethylhexyl) phthalate and bisphenol A exposure impairs mouse primordial follicle assembly in vitro. Environ Mol Mutagen. 2014; 55:343-353.

69 Chao $\mathrm{HH}$, Zhang XF, Chen B et al. Bisphenol A exposure modifies methylation of imprinted genes in mouse oocytes via the estrogen receptor signaling pathway. Histochem Cell Biol. 2012; 137:249-259.

70. Lobascio AM, Klinger FG, Scaldaferri ML et al. Analysis of programmed cell death in mouse fetal oocytes. Reproduction. 2007; 134:241-252.

71. Neufeld TP. TOR-dependent control of autophagy: biting the hand that feeds. Curr Opin Cell Biol. 2010; 22:157-168.

72. Rusten TE, Lindmo K, Juhász G et al. Programmed autophagy in the Drosophila fat body is induced by ecdysone through regulation of the PI3K pathway. Dev Cell. 2004; 7:179-192.

73. Scott RC, Schuldiner O, Neufeld TP. Role and regulation of starvation-induced autophagy in the Drosophila fat body. Dev Cell. 2004; 7:167-178.

74. Böhni R, Riesgo-Escovar J, Oldham S et al. Autonomous control of cell and organ size by CHICO, a Drosophila homolog of vertebrate IRS1-4. Cell. 1999; 97:865-875.

75. Richard DS, Rybczynski R, Wilson TG et al. Insulin signaling is necessary for vitellogenesis in Drosophila melanogaster independent of the roles of juvenile hormone and ecdysteroids: female sterility of the chico1 insulin signaling mutation is autonomous to the ovary. J Insect Physiol. 2005; 51:455-464.

76. Stocker H, Radimerski T, Schindelholz B et al. Rheb is an essential regulator of S6K in controlling cell growth in Drosophila. Nat Cell Biol. 2003; 5:559-565.

77. Werz C, Köhler K, Hafen E et al. The Drosophila SH2B family adaptor Lnk acts in parallel to chico in the insulin signaling pathway. PLoS Genet. 2009; 5:e1000596.

78. Wang $\mathrm{H}$, Wan $\mathrm{H}, \mathrm{Li} \mathrm{X}$ et al. Atg7 is required for acrosome biogenesis during spermatogenesis in mice. Cell Res. 2014; 24:852-869.

79. De Felici M, Lobascio AM, Klinger FG. Cell death in fetal oocytes: many players for multiple pathways. Autophagy. 2008; 4:240-242.

80. Hułas-Stasiak M1, Gawron A. Follicular atresia in the prepubertal spiny mouse (Acomys cahirinus) ovary. Apoptosis. 2011; 16:967-975.

81. Hertig AT, Adams EC. Studies on the human oocyte and its follicle. I. Ultrastructural and histochemical observations on the primordial follicle stage. J Cell Biol. 1967; 34:647-675.

82. Wassarman PM, Albertini DF. The Mammalian Ovum. NY: Raven Press. 1994

83. Chen Y, Breen K, Pepling ME. Estrogen can signal through multiple pathways to regulate oocyte cyst breakdown and primordial follicle assembly in the neonatal mouse ovary. J Endocrinol. 2009; 202:407-417.

84. Lei L, Spradling AC. Mouse oocytes differentiate through organelle enrichment from sister cyst germ cells. Science. 2016; 352:95-99. 